\title{
Semantic and associative factors in probability learning with words*
}

\author{
LOWELL M. SCHIPPER, BRUCE L. HANSON†, GLENN TAYLOR \\ and JACK A. THORPE \\ Bowling Green State University, Bowling Green, Ohio 43403
}

\begin{abstract}
Using a probability-learning technique with a single word as the cue and with the probability of a given event following this word fixed at .80, it was found (1) that neither high nor low associates to the original word and (2) that neither synonyms nor antonyms showed differential learning curves subsequent to original learning when the probability for the following event was shifted to .20. In a second study when feedback, in the form of knowledge of results, was withheld, there was a clear-cut similarity of predictions to the originally trained word and the synonyms of both high and low association value and a dissimilarity of these words to a set of antonyms of both high and low association value. Two additional studies confirmed the importance of the semantic dimension as compared with association value as traditionally measured.
\end{abstract}

In two preliminary studies (Hanson, Schipper, \& Brislin, 1969), words were used as stimuli, or predictors, in a multiple probability-learning situation. In the first study, one word, fast, was followed by a particular to-be-predicted event (E) a low percentage of the time; a second word, big, was followed by $\mathrm{E}$ a somewhat higher percentage of the time; and a third word, rough, was followed by $E$ a relatively high percentage of the time. In the second study, only the words big and fast were used as predictors with only high and low probabilities of $E$ arranged in a counterbalanced order. Following training, Ss were presented synonyms and antonyms with high and low association values and neutral words in a manner somewhat like that used originally by Razran (1949) in investigating semantic generalization effects.

Conditioning work similar to the paradigm used here was described in summary fashion by Bousfield (1961) followed by a discussion and what might be called a rejoinder by Osgood (1961). Additionally, Jenkins (1963) presented an excellent summary of methodology and then current findings of research with mediated associations at Cofer's second conference on verbal learning and behavior. It seems fair to say that Bousfield and Osgood would have differed in their predictions of the outcome of the two preliminary studies (Hanson, Schipper, \& Brislin, 1969). The former would have emphasized the importance of the degree of association and the latter, the importance of meaning.

The principal reason for using a probability-learning technique with words rather than with other abstract symbols was that considerable mediated learning could take place during training and this training could be

*The authors are indebted to Professors Charles N. Cofer and John F. Hall, whose comments greatly enhanced an earlier form of this article.

Now at Bell Telephone Laboratories, Holmdel. New Jersey 07733 . measured in subsequent testing situations. Specifically, training to a particular word might implicitly train to synonyms and antonyms of high and low association values. Of course, mediated learning could extend to more than those combinations, but the dimensions defined by extremes of antonymity and synonymity and by low and high association seemed well defined, easily measured, and important to an understanding of the effect of training on original and related material used subsequent to training.

The effect described here is similar to that of classical stimulus generalization. However, emphasis now is on what occurs in training rather than on an assumption of relationships of generalized stimuli to an original stimulus. Additionally, there is the possibility of "negative generalization," i.e., a level of responding below or in the direction opposite to that of positive generalization measured from some zero or neutral level.

In the first experiment to be described here, a single word was "conditioned" with a high level of noncontingent "reinforcement." It was hypothesized that an abrupt shift to a low level of "reinforcement" with a new word would result in different acquisition rates to synonyms and antonyms with high and low association values. In the second experiment, original training was similar to that in Experiment I. After the original training, however, each $\mathrm{S}$ was shown both synonyms and antonyms (and a neutral word) without feedback (or "reinforcement") and was required to predict the appropriate event to follow each word. A complete set of predictions for the outcomes of the experiments is given in Table 1.

\section{METHOD}

Subjects

All Ss were male volunteers from introductory courses in 
Table 1

\begin{tabular}{|c|c|c|}
\hline Comparison & & Analy sis \\
\hline $\mathrm{S}+$ vs $\mathrm{A}+$ & $\begin{array}{r}1 \mathrm{a} \\
\mathrm{b}\end{array}$ & $\begin{array}{l}\mathrm{S}+>\mathrm{A}^{+} \text {on semantic scale } \\
\mathrm{S}+=\mathrm{A}^{+} \text {on association scale }\end{array}$ \\
\hline $\mathrm{S}+$ vs $\mathrm{A}-$ & 2 & $\begin{array}{c}\mathrm{S}+>\mathrm{A}-\mathrm{on} \text { semantic and on } \\
\text { association scales }\end{array}$ \\
\hline $\mathrm{S}+$ vs $\mathrm{S}-$ & $\begin{array}{r}3 \mathrm{a} \\
\mathrm{b}\end{array}$ & $\begin{array}{l}S+=S-\text { on semantic scale } \\
S+>S-\text { on association scale }\end{array}$ \\
\hline $\mathrm{S}-$ vs $\mathrm{A}+$ & $\begin{array}{r}4 \mathrm{a} \\
\mathrm{b}\end{array}$ & $\begin{array}{l}\mathrm{S}->\mathrm{A}+\text { on semantic scale } \\
\mathrm{S}-<\mathrm{A}+\text { on association scale }\end{array}$ \\
\hline$S-$ vs $A-$ & $\begin{array}{r}5 \mathrm{a} \\
\mathrm{b}\end{array}$ & $\begin{array}{l}\mathrm{S}->\mathrm{A}-\text { on semantic scale } \\
\mathrm{S}-=\mathrm{A}-\text { on association scale }\end{array}$ \\
\hline$A+$ vs $A-$ & $\begin{array}{r}6 \mathrm{a} \\
\mathrm{b}\end{array}$ & $\begin{array}{l}A^{+}=A-\text { on semantic scale } \\
A^{+}>A-\text { on association scale }\end{array}$ \\
\hline
\end{tabular}

Note-The letter indicates whether the word is a synonym (S) or an antonym $(A)$. The sign indicates whether the word is a high associate (+) or a low associate (-). A > sign for Experiment I means that the acquisition curve at the new "reinforcement" level would be higher for the first word described as compared with the second word. Thus, the curve for a high-association synonym would be higher than the curve for a high-association antonym in Line Ia. In Experiment II, > and < mean more or fewer predictions, respectively, of a particular type.

psychology at the Pennsylvania State University and were run in small groups. Instructions to Ss were of the "neutral" variety in that they were told simply to try to be correct in their predictions as often as possible.

\section{Stimuli}

In both of the present studies, $S$ was trained to predict the occurrence of slides showing either a star or a circle after having seen the word joy on the immediately preceding slide. The word joy was selected as a stimulus, or cue, because it had synonyms and antonyms of comparably high and low association value. Specifically, associates and their frequencies, given joy, were: happiness $-81 / 500$, elation-2/500, sorrow-72/500, and grief-8/500 (Palermo \& Jenkins, 1964). Restriction of responses to synonyms gave frequencies of happiness-23/50 and elation-1/50 (Jenkins \& Palermo, 1965). Restriction to antonym responses gave sorrow-28/50 and grief-1/50 (Jenkins \& Palermo, 1964). The word further appeared on none of the lists and was selected for its semantic and associative neutrality to joy.

\section{EXPERIMENT I}

All Ss $(N=182)$ received 75 probability-learning trials with the stimulus word joy. Four of every five trials were followed by a slide showing a five-pointed star $\left(\pi_{1}\right.$ $=.80$ ). One randomly selected trial in each block of five was followed by a circle.

The Ss predicted the star or circle each time joy appeared on the screen by checking one of two columns on an answer sheet. Slides were projected using a Kodak Carousel projector with a $3-\mathrm{sec}$ on time and a $.5-\mathrm{sec}$ intertrial interval. Time intervals were controlled by three Hunter timers (Model 100-B). The projector was programmed using paper tape.

Following this initial training, Ss were retrained with one of the following six words: joy, $\mathrm{N}=28$, happiness,
$\mathrm{N}=32$, elation, $\mathrm{N}=31$, sorrow, $\mathrm{N}=30$, grief, $\mathrm{N}=30$, or further, $N=31$. Retraining was carried out using $\pi_{1}=$ .20 (star), with the complementary .80 (circle). The transition from initial training to retraining was made without stopping and without warning and continued for another 75 trials.

\section{Results and Discussion of Experiment I}

Curves for Parts 1 and 2 of the first experiment are shown in Fig. 1. Learning data for each set of curves was to the single word joy with $\pi_{1}=.80$ followed by $\pi_{1}=$ .20 with the second word indicated as the appropriate parameter. The retraining data of the second half of Fig. 1 are also summarized in Fig. 2 using 25 trial blocks to present a better picture of overall trends for the six cue words. Analyses of these six curves showed reliable differences among the five new words and the original joy. Additionally, it appeared that the neutral word, further, was responded to more like the antonyms than the synonyms.

A final summary of Experiment $I$ is provided by the single first trial predictions immediately after the shift from joy. The initial responses were: joy, 75\%; happiness, 69\%; elation, 68\%; grief, 53\%; sorrow, 50\%; and further, $45 \%$. These percentages reflect the proportion of $\mathrm{Ss}$ in each treatment that made star predictions on the initial presentation of the second word.

It seems quite clear from this experiment that grossly changing probabilities from .80 to .20 had an almost immediate effect which far surpassed the implicit training of the associated stimulus words. Only within the. first 10 trials or so were the effects of synonymity-antonymity really detectable, and throughout the second training series only the originally trained word was set apart from the other five.

\section{EXPERIMENT II}

Because of the demonstrated lack of effect of the associative and semantic variables in Experiment $I$, apparently as a function of the overpowering effect of the second reinforcement ratio, Experiment II was arranged using an earlier decision-making paradigm (Schipper, 1967) in which feedback was withheld after initial training.

Eighty training trials, eight blocks of 10 trials, with $\pi_{1}$ $=.80$ were used with star and circle again following joy. With updated equipment, $S$ responded by pressing one of two buttons, mounted on a small box, to indicate his prediction. The intertrial interval remained the same, but projection time was reduced to $2 \mathrm{sec}$.

All Ss $(\mathrm{N}=26)$ were run in small groups, and all were volunteers from classes in introductory psychology at the Pennsylvania State University.

Original instructions were the same as in Experiment I with two exceptions. The new method of responding 
was explained, and after the initial training to joy, the experiment was stopped and Ss were told that they would see different words, that they were still to predict
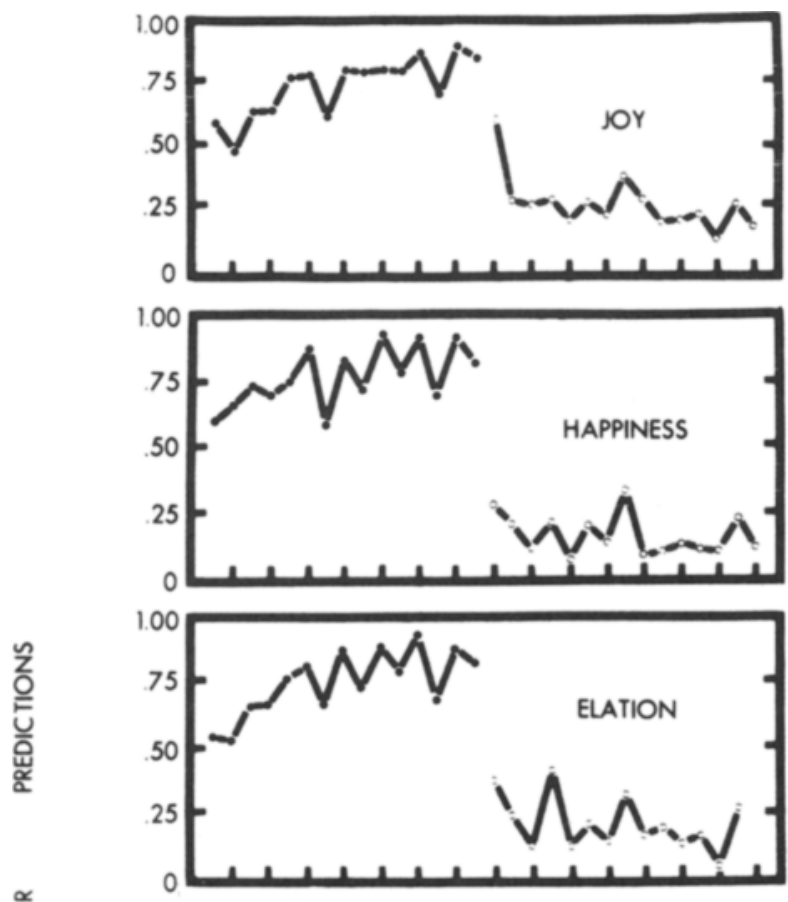

$\frac{2}{4}$
$\frac{1}{2}$
을
$\frac{0}{0}$
$\frac{2}{2}$
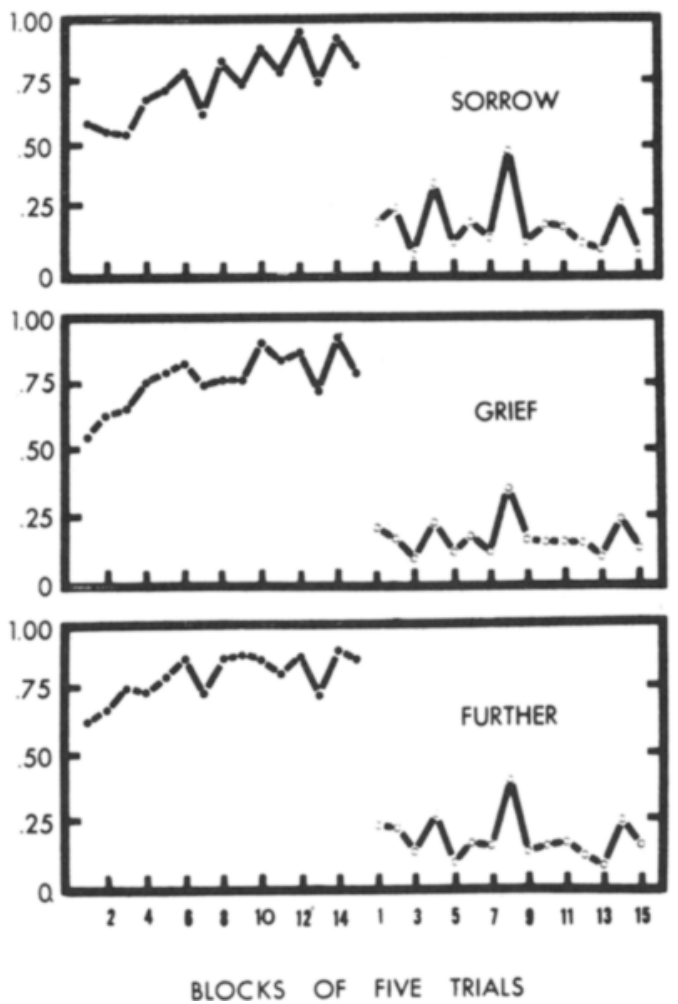

Fig. 1. Learning $\left(\pi_{1}=.80\right)$ and relearning $\left(\pi_{1}=.20\right)$ curves for Experiment I. Original training for all figures was to the single word joy'. Subsequent training was to the word shown in each block.

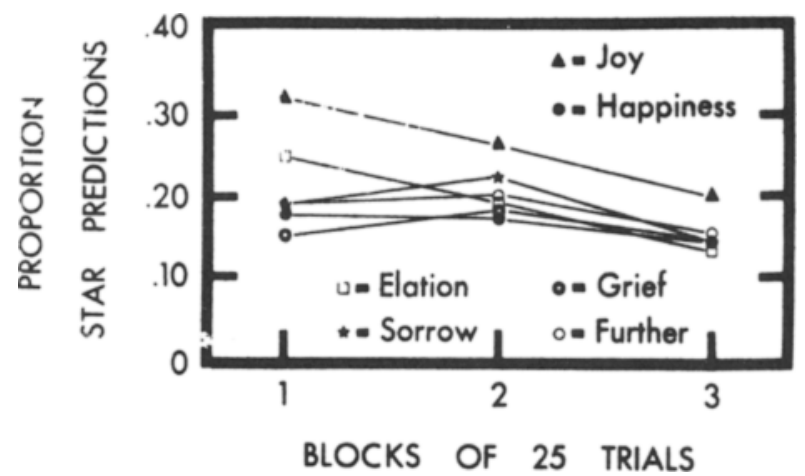

Fig. 2. Relearning curves for Part 2 of Experiment I plotted in 25-trial blocks.

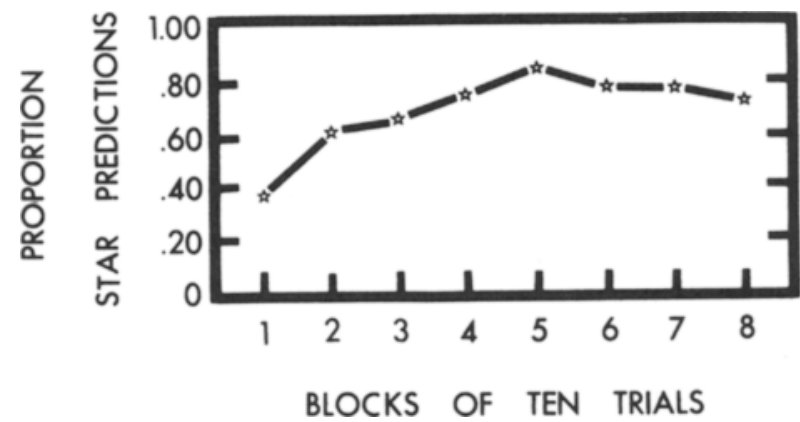

Fig. 3. Learning ( $\left.\pi_{1}=.80\right)$ curve for Experiment II $(\mathrm{N}=26)$.

stars and circles, but that these slides had been removed after each word.

In this second part of Experiment II, Ss made 60 predictions, 10 with each of the six words used in Experiment I presented in a random arrangement of 10 blocks of the six words. Again, Ss were instructed to "try to be correct as often as possible" even though no feedback as to right or wrong predictions was to be forthcoming.

\section{Results and Discussion of Experiment II}

The learning curve showing star predictions to the initial cue word, joy, is shown in Fig. 3. This curve, demonstrating greater stability than those of the first experiment, was based on trial blocks of Size 10, rather than 5, and showed no unusual characteristics. The average level of responding over the last three blocks was just over $76 \%$.

Table 2 is a distribution showing the number of star predictions by Ss to the 10 presentations of each of the stimulus words in Part 2 of the experiment. The distributions for joy, happiness, and clation, all three quite similar, are sharply negatively skewed. The distributions for sorrow, grief, and further are also similar to one another, but considerably more platykurtic with a trend toward bimodality for the two antonyms. 
Table 2a

Each S's Star Predictions in Part 2 of Experiment II

\begin{tabular}{rrrrrrr}
\hline$S$ & J & H & E & S & G & F \\
\hline 1 & 8 & 10 & 7 & 4 & 5 & 8 \\
2 & 10 & 10 & 10 & 1 & 2 & 10 \\
3 & 7 & 10 & 10 & 10 & 10 & 3 \\
4 & 8 & 10 & 9 & 0 & 0 & 0 \\
5 & 9 & 10 & 7 & 9 & 10 & 5 \\
6 & 9 & 8 & 10 & 1 & 1 & 8 \\
7 & 10 & 10 & 9 & 0 & 0 & 0 \\
8 & 8 & 7 & 9 & 5 & 1 & 10 \\
9 & 9 & 10 & 10 & 0 & 0 & 10 \\
10 & 10 & 10 & 10 & 2 & 10 & 7 \\
11 & 9 & 6 & 4 & 8 & 8 & 7 \\
12 & 7 & 8 & 7 & 4 & 4 & 5 \\
13 & 8 & 0 & 9 & 9 & 9 & 9 \\
14 & 10 & 10 & 10 & 1 & 2 & 9 \\
15 & 9 & 9 & 10 & 4 & 6 & 9 \\
16 & 10 & 10 & 10 & 7 & 8 & 0 \\
17 & 8 & 9 & 9 & 4 & 6 & 8 \\
18 & 9 & 7 & 9 & 9 & 9 & 4 \\
19 & 5 & 7 & 7 & 8 & 7 & 6 \\
20 & 9 & 8 & 7 & 1 & 1 & 9 \\
21 & 9 & 10 & 9 & 6 & 7 & 10 \\
22 & 10 & 10 & 9 & 2 & 3 & 4 \\
23 & 9 & 9 & 7 & 0 & 8 & 8 \\
24 & 8 & 7 & 5 & 9 & 8 & 2 \\
25 & 10 & 10 & 10 & 0 & 0 & 0 \\
26 & 7 & 4 & 8 & 6 & 9 & 6 \\
$\bar{X}$ & 8.65 & 8.42 & 8.50 & 4.23 & 5.15 & 6.04 \\
\hline
\end{tabular}

Table $2 b$

Distribution of $S s$ in Terms of Number of Ss Making 0-10 Star Predictions for Each Word

\begin{tabular}{lrrrrrrrrrrr} 
& 0 & 1 & 2 & 3 & 4 & 5 & 6 & 7 & 8 & 9 & 10 \\
\hline Joy & 0 & 0 & 0 & 0 & 0 & 1 & 0 & 3 & 6 & 9 & 7 \\
Happiness & 1 & 0 & 0 & 0 & 1 & 0 & 1 & 4 & 3 & 3 & 13 \\
Elation & 0 & 0 & 0 & 0 & 1 & 1 & 0 & 6 & 1 & 8 & 9 \\
Sorrow & 5 & 4 & 2 & 0 & 4 & 1 & 2 & 1 & 2 & 4 & 1 \\
Grief & 4 & 3 & 2 & 1 & 1 & 1 & 2 & 2 & 4 & 3 & 3 \\
Further & 4 & 0 & 1 & 1 & 2 & 2 & 2 & 2 & 4 & 4 & 4 \\
\hline
\end{tabular}

Correlated-sample $\mathrm{t}$ tests $(\mathrm{df}=25)$ between all test words showed no statistically significant differences between joy, happiness, and elation $(\mathrm{p}>.20$ for all three pairs) and between sorrow, grief, and further ( $p>.05$ for all three pairs), but there were highly reliable differences between any word in the first set and any word in the second set (all ps $<.02$ ). Thus, responses to synonyms and antonyms were different, independent of association value, but responses to antonyms and the neutral word were about the same.

First trial predictions in the second half of Experiment II were similar to those in Experiment I. These percentages were joy, 85\%; happiness, $73 \%$; elation, $65 \%$; grief, $54 \%$; sorrow, $46 \%$; and further, $58 \%$.

Of the $26 \mathrm{Ss}$, about half fit the pattern described earlier, i.e., large numbers of star predictions to synonyms and joy, and fewer predictions to antonyms and further. Six Ss, however, showed an opposite trend.

\section{GENERAL DISCUSSION}

The initial speculations concerning the importance of the two factors as determinants of responding in the second phase of Experiment I were that both associative strength and semantic value would have differentiated the slopes of the reacquisition curves. It was hypothesized that if associative strength were a more potent factor than semantic value, the curves for happiness and sorrow would have been more like the reacquisition curve for joy than would the curves for elation and grief. In Experiment II, the corresponding hypothesis was that proportions of similar responses for happiness and sorrow would have been closer to the proportions of responses to joy. In both experiments, if semantic value were the most important factor, then greater similarity would have been shown by happiness and elation in comparison with joy than by sorrow and grief. This latter hypothesis seems, indeed, to have been more tenable.

\section{POSTSCRIPT}

Because of what might be termed a limited sample of stimuli in both Experiments I and II, two additional studies were conducted. One of these additional studies, the last to be reported here, was carried out at the Pennsylvania State University using equipment and technique similar to that of the second experiment. The following study was carried out at Bowling Green State University using somewhat different projection equipment but a similar keypressing mode of response.

\section{Experiment III}

Eight different words were selected, each with a higher association antonym than synonym. Words were projected on a small screen display (Industrial Electronics Engineers, Inc., one-plane readout) for 80 trials, and each was followed by a $\Theta$ or a $\oplus$ (identified as square and circle) $80 \%$ and $20 \%$ of the time, respectively. Responding was with buttons also coded $\square$ and $\oplus$. Eight male Ss, volunteers from introductory psychology courses at Bowling Green State University, were run individually in each of four treatments, one $S$ with each word in each treatment. In $T_{1}$, each $S$ was given 10 presentations of an antonym and a synonym after training; in $T_{2}$, a synonym and a neutral word; in $T_{3}$, an antonym and a neutral word; and in $T_{4}$, an antonym, a synonym, and a neutral word.

Table 3 gives a summary of these results. Proportions of $\square$ responses for the last 10 trials in training are presented in addition to the overall proportions for all trials. The summary data at the bottom of the table seem unambiguous when comparing the relatively low association synonyms against the higher association antonyms. Semantic value is clearly the more important dimension when compared with association value, 
Table 3

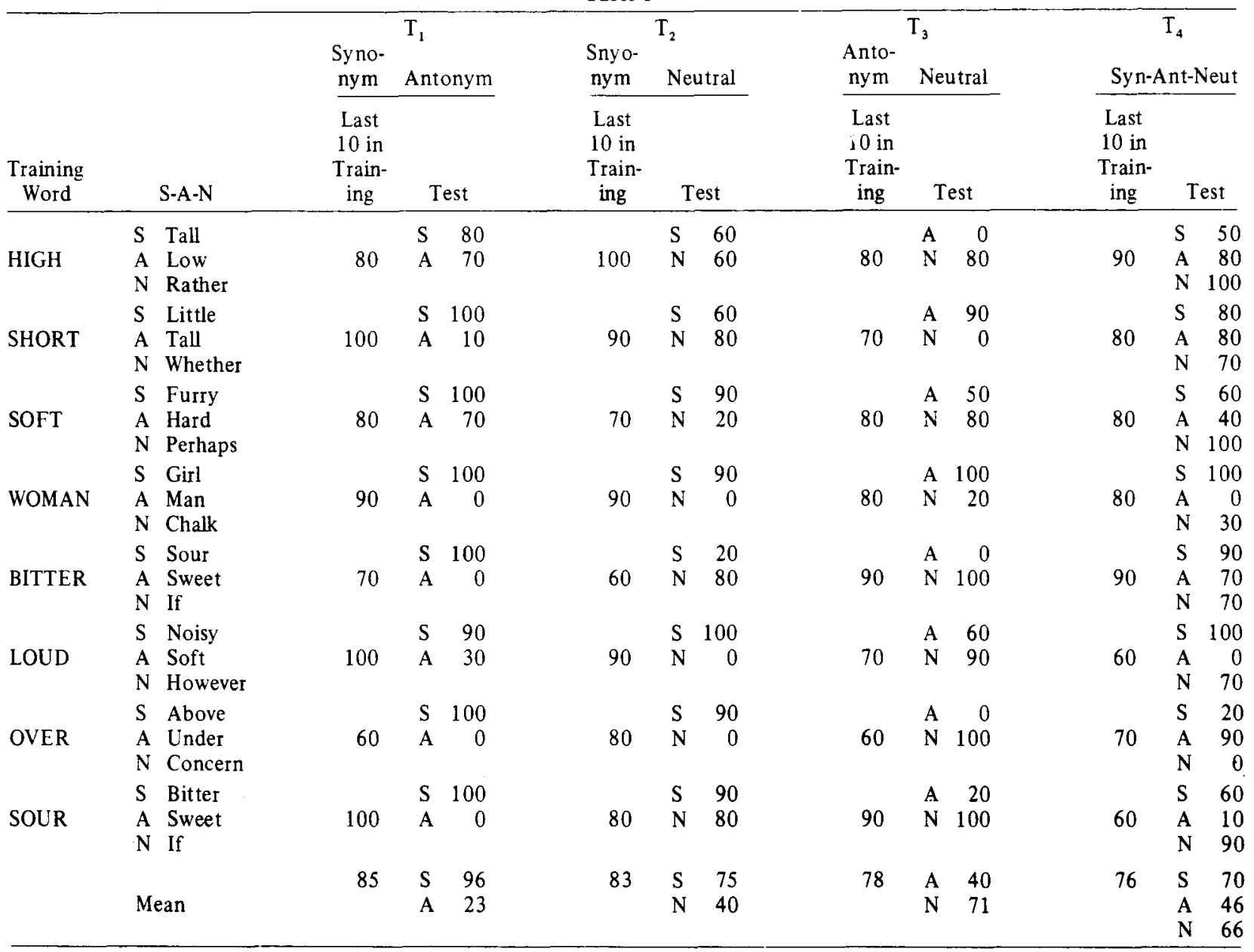

although variability among Ss (and words) is high. Overall differences in $T_{1}, T_{2}$, and $T_{3}$, respectively, are statistically reliable using simply chi square $(\mathrm{df}=1)$ with pooled frequencies from the eight $\mathrm{Ss}$ in each of the response categories.

\section{Experiment IV}

Two words, rough and buy, were trained simultaneously. Fifteen blocks of 10 successive trials each contained a randomization of five presentations of the word rough and five presentations of buy. In $\mathrm{T}_{1}(\mathrm{~N}$ $=16$ males, 28 females $)(.80, .80)$, each word was followed randomly by a star four times and by a blank slide once in each successive 5-trial presentation of that word. In $\mathrm{T}_{2}(\mathrm{~N}=16$ males, 28 females $)(.80, .20)$, rough was starred four of five times (as before) but buy was starred only once. In $T_{3}(\mathrm{~N}=15$ males, 28 females $)(.20$, .20), rough and buy were each starred $20 \%$ of the time.

After training, approximately half of each treatment group ( 8 males, 14 females) saw a combination of neutral words (citizen and again) and synonyms (purchase and coarse) of the originally trained words. The other half saw a combination of the same two neutral words and antonyms (sell and smooth) of the originally trained words. These four words were presented in the posttraining sessions in 10 blocks of four trials each. Confirmation of predictions in this part

Table 4

Percentages of Positive Responses After Training*

\begin{tabular}{ccccccc}
\hline \multicolumn{2}{c}{ Treatment } & Purchase & Sell & Coarse & Smooth & Citizen/Again \\
\hline $\mathrm{T}_{1}$ & $80-80$ & $\mathrm{~S}-\mathrm{N}$ & 71 & & 71 & 75 \\
$\mathrm{~T}_{2}$ & $80-20$ & $\mathrm{~S}-\mathrm{N}$ & 34 & & 72 & 51 \\
$\mathrm{~T}_{3}$ & $20-20$ & $\mathrm{~S}-\mathrm{N}$ & 32 & & 26 & 28 \\
$\mathrm{~T}_{1}$ & $80-80$ & $\mathrm{~A}-\mathrm{N}$ & & 79 & & 77 \\
$\mathrm{~T}_{2}$ & $80-20$ & $\mathrm{~A}-\mathrm{N}$ & & 44 & & 59 \\
$\mathrm{~T}_{3}$ & $20-20$ & A-N & & 26 & & 26 \\
\hline
\end{tabular}

*In $T_{2}, 80-20, S-N$ and $T_{2}, 80-20, A-N$ the originally' trained word rough had been "reinforced" at $\pi=.80$ and the word buy at $\pi=.20$. 
of the experiment was withheld. as in Experimem 11.

All Ss. volunteers from introductory pstcholos! courses at PSU. Were run in small groups ranging in sizo from one to eight with an average group size of hetween two and three Ss.

The results of this experiment are summarized in Table 4. Comparisons can be made with the appropriate treatments in Hanson. Schipper, and Brislin (1960) Experiment 1). In that study, although three different words were trained simultaneously with $\pi=.14, .43$. and .86 , and although the originally trained words were repeated in the test trials, two of the three treatments with the three words, the synonym-neutral and antonym-neutral treatments, are analogous to the $T_{2}$ treatments $(\pi=.20$ and .80$)$ used here.

In the first study, positive responses to the synonyms at $\pi=.14$ and $\pi=.86$ were .35 and .77 , respectively. In the current experiment at $\pi=.20$ and $\pi=.80$, positive responses were .34 and .72 , respectively. These are certainly reasonable ball park similarities considering the various differences in the two studies.

Positive responses to the antonyms at $\pi=.14$ and $\pi=$ .86 were .37 and .41 , respectively, as compared with .44 and .45 , respectively, for $\pi=.20$ and $\pi=.80$ here.

Of importance seems to be the high reliability in comparing the proportions of positive responses in the test sequences for the two different synonyms and antonyms in $T_{1}$ and. $T_{3}$. Purchase and coarse are each responded to positively at the same .71 rate when $\pi=$ .80. Sell and smooth are responded to at only slightly different rates, .79 compared with .77 as antonyms. Sell and smooth give proportions of .32 and .26 in $\mathrm{T}_{3, \mathrm{~S}-\mathrm{N}}$ and .26 and .26 in $\mathrm{T}_{3, \mathrm{~A}-\mathrm{N}}$.

Of additional importance seems to be the overall response rate to the neutral words, most probably as a function of the overall value of $\pi$ used in training. The average responses to the neutrals in the 80-80, 80-20, and 20.20 treatments are $.72, .50$, and .25 , respectively.

Speculation leads us to believe that training involving the use of words as cues implies that reinforcement (or correctness) for a particular word also implies a mediated kind of punishment (or wrongness) for the somamically opposite word and that this process takes placindependent of association value. It also seems that porhaps the utility of using association value in traditional verbal learning studies may be highly peculiar wh the very nuture of that type of study and not to other ippes of learning situations. Lists may have to be modified when more than one is used in this type of study to take account of possible semantic relationships as well as traditional measures of association.

\section{REFERENCES}

Bousfield. $W$. A. The problem of meaning in verbal learning. In C. N. Cofer (Ed.). Verbal learning and verbal behalior. New York: McGraw-Hill. 1961. Pp. 81-91.

Hanson. B. L.. Schipper. L. M.. \& Brislin, R. W. Probability learning with words. Psychonomic Science, 1969, 16, 300-301.

Jenkins. J. J. Mediated associations: Paradigms and situations. In C. N. Cofer and Barbara S. Musgrave (Eds.), Verbal behavior and learning. New York: McGraw-Hill, 1963. Pp. 210-245.

Jenkins. J. J., \& Palermo. D. S. Contrast responses to the stimulus words of the Palermo-Jenkins word association list. Research Bulletin No.43, National Institute of Child Health and Human Development, United States Public Health Service, June 1964.

Jenkins, J. J., \& Palermo, D. S. Synonym responses to the stimulus words of the Palermo-Jenkins word association list. Research Bulletin No. 55, National Institute of Child Health and Human Development, United States Public Health Service, January 1965.

Osgood, C. E. Comments on Professor Bousfield's paper. In C. N. Cofer (Ed.), Verbal learning and verbal behavior. New York: McGraw-Hill, 1961. Pp. 91-106.

Palermo, D. S., \& Jenkins, J. J. Word association norms. Minneapolis: University of Minnesota Press, 1964.

Razran, G. Semantic and phonetographic generalizations of salivary conditioning to verbal stimuli. Journal of Experimental Psychology, 1949, 39, 642-652.

Schipper, L. M. Extreme probabilities in learning and decision making. Journal of Experimental Psychology, 1967, 73, 149-151.

(Received for publication February 16, 1973; accepted February 25, 1973.) 